\title{
REPENSANDO A HISTÓRIA COMPARADA DA AMÉRICA LATINA*
}

\author{
Maria Ligia Coelho Prado \\ Depto. de História - FFLCH/USP
}

\section{Resumo}

Este artigo discute abordagens e métodos da História Comparada, in dicando possibilidades e limites dessa escolha. Apresenta diferentes enfoques assumidos por sociólogos e cientista políticos, insistindo nas particularidades do ofício do historiador. Debruça-se de forma particular sobre problemas específicos próprios da História da América Latina. Estabelece diálogos com os desafios propostos pelas histórias conectadas.

\section{Pallavras-Chave}

História Comparada • América Latina • Histórias Conectadas

\section{Abstract}

This article deals with methods and approaches to Comparative History, presenting possibilities and limits of this choice. It shows social science's different approaches, emphasizing the particularities of the metier $d u$ historien. It considers some issues concerning Latin American History. It debates also the challenges brought by connected histories.

\section{Keywords}

Comparative History $\bullet$ Latin America • Connected Histories

\footnotetext{
* Agradeço a Maria Helena Capelato, Mary Anne Junqueira, Marcelo Cândido da Silva e Stella Maris Scatena Franco pelas contribuições a este artigo.
} 


\section{Apresentando o problema}

Comparar o Brasil com os demais países da América Latina sempre me pareceu um desafio estimulante. Na medida em que a história de cada país latino-americano corre paralelamente às demais, atravessando situações sincrônicas bastante semelhantes - a colonização ibérica, a independência política, a formação dos Estados Nacionais, a preeminência inglesa e depois a norte-americana, para ficar nas temática tradicionais - não há, do meu ponto de vista, como escapar às comparações. Em vez de manter os olhos fixos na Europa, é mais eficaz, para o historiador, olhar o Brasil ao lado dos países de colonização espanhola.

Assim fez Manoel Bomfim que, em O Brasil na América. Caracterização da Formação Brasileira (1929), estudou o processo histórico brasileiro, da colônia à independências política, marcando as diferenças entre as duas Américas Ibéricas. ${ }^{1}$ Do mesmo modo, Sérgio Buarque de Holanda que, nos clássicos Raízes do Brasil (1936) e Visão do Paraíso (1959), para pensar o Brasil, também comparou as Américas Portuguesa e Espanhola. ${ }^{2} \mathrm{~A}$ originalidade dessas reflexões e as novas questões propostas são devedoras da escolhida abordagem que é abrangente e ampliada. Desde já, assinalem-se duas condições imperativas para a efetivação de um trabalho de história comparada, presentes nesses livros: um elenco de problemas substantivos colocados a priori e uma sólida erudição.

Entretanto, de um modo geral, dentro ou fora do Brasil, a produção sobre história comparada é pequena e intermitente. Por outro lado, alguns textos clássicos de autores europeus que utilizaram a comparação são bastante conhecidos. No século XIX, em A democracia na América, Alexis de Tocqueville realizou uma obra extraordinária, em parte, porque se apoiou na comparação entre os Estados Unidos e a Europa (particularmente a França) para refletir sobre o tema escolhido. ${ }^{3}$ No século XX, o historiador inglês de grande prestí-

\footnotetext{
${ }^{1}$ BOMFIM, Manoel. O Brasil na América. Caracterização da formação brasileira. $2^{\mathrm{a}}$. ed., Rio de Janeiro: Topbooks, 1997.

${ }^{2}$ HOLANDA, Sérgio Buarque de. Raízes do Brasil. $22^{\mathrm{a}}$ ed., Rio de Janeiro: José Olympio, 1991. HOLANDA, Sérgio Buarque de. Visão do Paraíso. Os motivos edênicos no descobrimento e colonização do Brasil. $5^{\text {a }}$ ed., São Paulo: Brasiliense, 1992.

${ }^{3}$ TOCQUEVILlE, Alexis de. A democracia na América. Trad. Neil Ribeiro da Silva. $3^{\mathrm{a}}$ ed., São Paulo: Edusp, 1987.
} 
gio, Eric Hobsbawm, também comparou ao construir "as eras das revoluções, do capital, dos impérios e dos extremos", contribuindo para ampliar e inovar a visão sobre essas temáticas. ${ }^{4}$

Mas é indiscutível que a história comparada provoca resistências entre a maioria dos historiadores. Para entendê-las, é preciso voltar à própria construção do campo da História no século XIX. Marcavam-se as fronteiras desse saber, enfatizando-se a busca da verdade objetiva baseada nas fontes documentais e a singularidade dos fatos históricos. Desse modo, os acontecimentos eram vistos como únicos, não se ajustando a generalizações ou modelos elaborados a partir de variáveis constantes. Teorizações provenientes da análise de vários casos deveria ser a tarefa de outras ciências sociais, como a sociologia, a antropologia ou a ciência política. A questão que se esconde por trás dessas manifestações vincula-se à idéia da pouca eficácia, ou mesmo, da inadequação da comparação para a compreensão do processo histórico. Nesse sentido, o historiador em seu ofício deve valorizar os dados empíricos (suas fontes) que configuram as singularidades históricas.

Ao lado dessa questão, as práticas historiográficas que recortam o espaço nacional como o "ideal" vêm sendo acolhidas, desde o século XIX, pela maioria dos pesquisadores. A perspectiva de tomar as fronteiras da nação como os limites naturais estabelecidos para a pesquisa histórica é ainda a escolha majoritária. A força persuasiva do nacionalismo continua presente e fortemente estabelecida tanto no cenário da política como também no mundo universitário, onde a centralidade das disciplinas referidas à história nacional é prova cabal dessa visão hegemônica.

Em 1924, o historiador belga, Henri Pirenne, apontava com vigor para esse problema. Sob o impacto da inaudita violência da Primeira Guerra, provocada pelos nacionalismos em concorrência, criticava os horizontes da história nacional e argumentava em favor da história comparada. Enfatizava que o confinamento da pesquisa histórica dentro dos espaços estritamente nacionais impe-

\footnotetext{
${ }^{4}$ Ver: HOBSBAWM, Eric. J. A era das revoluções: Europa, 1789-1848. Trad. Maria Tereza Lopes Teixeira. $7^{a}$ ed., Rio de Janeiro: Paz e Terra, 1989; A era do capital: 1848-1875. Trad. Luciano Costa Neto. Rio de Janeiro: Paz e Terra, 1977; A era dos impérios: 18751914. Trad. Sieni M. Campos e Yolanda S. Toledo. $3^{\text {a }}$ ed., Rio de Janeiro: Paz e Terra, 1992; Era dos extremos: o breve século XX: 1914-1991. Trad. Marcos Santarrita. São Paulo: Companhia das Letras, 1995.
} 
dia a compreensão da história do próprio país e se traduzia na falta de imparcialidade do historiador, produzindo "preconceitos políticos e de raça". Essa limitação condenava o historiador a "ignorar os laços que ligavam cada história nacional à história das outra nações". Para escapar a essas restrições, a história comparada era a solução, pois apenas ela seria capaz de permitir apreciar "o justo valor" e "o grau preciso de verdade científica" dos fatos estudados. Sua proposição era a de adotar para a história nacional, o ponto de vista da história universal. Desse modo, a história seria não apenas "mais exata", como "mais humana", e mostraria aos povos "a solidariedade de seus destinos, um patriotismo mais fraterno, mais consciente e mais puro". ${ }^{5}$

\section{Problemas de método}

As dificuldades de aceitação da história comparada - ao lado da já mencionada forte adesão do historiador ao recorte de seu objeto dentro do espaço nacional - relacionam-se também às incertezas sobre os procedimentos metodológicos de tal abordagem e à eficácia dos resultados.

Os advogados da história comparada reafirmam sua importância e interesse. Mesmo fora do campo dos historiadores, há depoimentos favoráveis, como o do antropólogo norte-americano, Sidney Mintz, que afirma: "A história nunca se repete exatamente, e cada acontecimento é, evidentemente, único; mas as forças históricas certamente podem se mover em rotas paralelas num mesmo tempo ou em diferentes temporalidades. A comparação de tais paralelos pode revelar regularidades de valor científico potencial". ${ }^{6}$

No entanto, os críticos da história comparada alertam para os enganos produzidos pelos procedimentos comparativos, levando, por exemplo, os pesquisadores a serem induzidos a assumir uma visão colada ao eurocentrismo. ${ }^{7}$

\footnotetext{
${ }^{5}$ PIRENNE, Henri. "De la méthode comparative en histoire. Discours prononcé à la séance d'ouverture du Ve Congrès International des Sciences Historiques. Bruxelles, 1923. PIRENNE, Henri. "La tâche de l'historien". Le Flambeau, vol. XIV, nº 8, 1931. pp. 5-22. ${ }^{6}$ MINTZ, Sidney. "Labor and sugar in Puerto Rico and in Jamaica, 1800-1850". Comparative Studies in Society and History, vol.1, no. 3, 1959, citado por FRENCH, J.; MÖRNER, M.; VIÑUELA, J. "Comparative Approaches to Latin American History". Latin American Research Review, vol. 17, n’ 2, p.57.

${ }^{7}$ Retomarei este tema mais adiante, ao abordar a perspectiva do historiador Serge Gruzinski.
} 
Edward Said indiretamente aponta para o olhar comparativo como responsável pela construção de um Oriente inventado pelo Ocidente. As visões negativas sobre o Oriente, elaboradas pelos "especialistas" europeus (sobretudo ingleses e franceses), particularmente no século XIX, que se contrapunham à "civilizada" Europa, expressavam a valoração hierarquizada que colocava o Ocidente num patamar acima do Oriente. Afirma Said que "o mais importante componente da cultura européia é precisamente o que faz aquela cultura hegemônica dentro ou fora da Europa: a idéia de uma identidade européia como superior em comparação com todos os povos e culturas não européias. Há em adição a essa visão, a hegemonia das idéias européias sobre o Oriente, elas mesmas reiterando a superioridade européia sobre o atraso do Oriente, e usualmente escondendo a possibilidade de que um pensador mais independente ou mais cético possa ter perspectivas diferentes sobre o assunto." 8

Essa mesma abordagem etnocêntrica pode ser detectada no influente livro de Gabriel Almond e Sidney Verba, The civic culture: political attitudes and democracy in five nations. ${ }^{9}$ Este é um estudo que aplica o conceito de cultura política à democracia e à cidadania, comparando as relações entre as atitudes dos indivíduos e o funcionamento da democracia em cinco países: México, Itália, Alemanha, Grã-Bretanha e Estados Unidos. Os autores se detêm fundamentalmente no conhecimento dos sistemas políticos, nos sentimentos em relação a esses sistemas e no desempenho dos cidadãos como atores políticos. Apoiando-se no paradigma construído, assumem a perspectiva de que a cultura política e as instituições democráticas anglo-saxônicas são superiores e universalmente desejáveis. Desse modo, não surpreende que, em suas conclusões, a cultura política "ideal" seja a dos Estados Unidos e a da Grã-Bretanha. Por outro lado, México, Itália e Alemanha "desviam-se" em graus variados do modelo edificado, sendo colocados em um patamar inferior no que se refere às atitudes frente à democracia e à cidadania.

A comparação, portanto, coloca desafios e demanda cautela. Uma entrada exemplar para a discussão sobre método comparativo em história, conti-

\footnotetext{
${ }^{8}$ SAID, Edward W. Orientalismo: o Oriente como invenção do Ocidente. Trad. Tomás R. Bueno. São Paulo: Companhia das Letras, 1990. p. 7.

${ }^{9}$ ALMOND, Gabriel A.; VERBA, Sidney. The civic culture: political attitudes and democracy in five nations. Boston: Little Brown and Company, 1965.
} 
nua sendo o inspirado artigo de Marc Bloch, Pour une histoire comparée des sociétés européennes, escrito em 1928. ${ }^{10}$ Historiadores e cientistas sociais continuam tomando esse texto como referência fundamental. Bloch já havia experimentado a comparação em seu clássico, Os reis taumaturgos, de 1924, em que analisava o caráter sobrenatural atribuído ao poder real, especialmente na França e na Inglaterra, no período medieval. ${ }^{11}$

A proposta do artigo é a de demonstrar que o método comparativo se apresenta como "um instrumento técnico, de uso corrente, manejável e capaz de levar a resultados positivos". ${ }^{12} \mathrm{O}$ texto de Bloch assume uma dimensão militante, pois propõe que a história comparada, por seu valor e alcance, deva ser incorporada à grade curricular dos cursos de História das universidades. Conhecendo as dificuldades de sua aceitação, afirmava que os historiadores de sua geração, diferentemente dele, entendiam que a história comparada se apresentava como "um capítulo da filosofia da história ou da sociologia geral”.

Bloch, da mesma forma que Pirenne, ao propor a abordagem comparada estava fazendo a crítica da limitação das pesquisas aos espaços nacionais. Ambos estudaram a Idade Média, fator inconteste para libertá-los mais facilmente das amarras do nacional. Dizia Bloch que os historiadores que se debruçavam exclusivamente sobre a história nacional mantinham, entre eles, um diálogo de surdos, pois caminhavam de uma história nacional a outra sem que se ouvissem mutuamente. ${ }^{13}$ Provavelmente, Bloch, como muitos de sua gera-

\footnotetext{
${ }^{10}$ BLOCH, Marc. "Pour une Historie Comparée des societés européennes". In: Mélanges historiques. vol. 1, Paris: S.E.V.P.E.N., 1963. pp. 16-40. Ainda hoje, a história comparada continua a motivar debates e discussões entre os historiadores, permanecendo Marc Bloch como referência central para a questão. Esta importância pode ser percebida pelo Colóquio, realizado em Paris, em 1986, destinado a discutir especificamente a relevância dos trabalhos do historiador francês e da história comparada na atualidade. ATSMA, Hartmut; BURGUIÈRE, André. (Orgs.). Marc Bloch aujourd'hui: histoire comparé et sciences sociales [Contributions au Colloque international organisé à Paris du 16 au 18 juin 1986 par l'École des hautes études en sciences sociales et l'Istitut historique allemand]. Paris: Éd. de l'École des hautes études en sciences sociales, 1990.

${ }^{11} \mathrm{BLOCH}$, Marc. Os reis taumaturgos: o caráter sobrenatural do poder régio, França e Inglaterra. Trad. Júlia Mainardi. São Paulo: Companhia das Letras, 1993.

${ }^{12}$ BLOCH, Marc. "Pour une Historie Comparée des societés européennes". Op. cit., p.16.

${ }^{13}$ A mesma ruptura foi advogada por Pierre Chaunu que, nos anos 60, afirmou: "é preciso romper com os Estados" e propor a história "du desenclavement planétaire des civilizations et des cultures" in: L'expansion européenne du XIIIe.au XVe siècle. Paris, PUF, 1969, citado por GRUZINSKI, Serge, "Les mondes mêlés de la Monarchie catholique et autres 'connected histories' “. Annales HSS, n 1, janvier-février 2001. p. 88.
} 
ção, sofrera o golpe da desilusão provocada pela Primeira Guerra Mundial, abrindo espaço para indagações sobre os perigos dos nacionalismos responsáveis por aquela catástrofe.

Um dos exemplos por ele escolhido é paradigmático, pois afetava as convicções nacionalistas francesas. A monarquia carolíngia, berço da nacionalidade francesa, se apresentava com características originais se comparada à merovíngia que a precedeu no tempo. Os merovíngios mantinham o poder temporal separado da Igreja o que era percebido, por exemplo, nos atos laicos da coroação dos reis. Já os carolíngios recebiam a coroa sagrada pela unção do óleo santo. A hipótese de Bloch é que tal ritual havia sido absorvido por influência dos reis visigóticos da Espanha que, desde o século VII, recebiam a sacrossanta unção. Afirma que era incontestável o fato do reino franco, durante o século que assistiu à conquista árabe, ter recebido muita "gente comum" vinda da península ibérica. Ao lado delas, chegaram também padres que conheciam os hábitos políticos e religiosos da região que deixaram. Desse modo, pode levantar a hipótese de que algumas concepções sobre a realeza e seu papel, algumas idéias sobre a constituição da sociedade vassálica e sua utilização pelo Estado teriam aparecido primeiro na "Espanha" onde foram traduzidas nos textos legislativos e depois tomadas conscientemente pela entourage dos reis francos ou por eles mesmos. Apenas a comparação permitiu que ele levantasse problemas e hipóteses impossíveis de serem pensada se as (posteriores) fronteiras "nacionais" não tivessem sido ultrapassadas. ${ }^{14}$

O método comparativo supunha determinados procedimentos, a começar pela escolha de seu objeto. Para Bloch, deviam-se escolher dois ou mais fenômenos que parecessem, à primeira vista, apresentar certas analogias entre eles, em um ou vários meios sociais diferentes; em seguida, descrever as curvas de sua evolução, constatar as semelhanças e as diferenças e, na medida do possível, explicá-las à luz da aproximação entre uns e outros. De preferência, propunha estudar paralelamente sociedades vizinhas e contemporâneas,

\footnotetext{
${ }^{14}$ É preciso ressaltar que vários trabalhos publicados nos últimos anos têm sustentado que a distância que separa os merovíngios dos carolíngios não é tão grande quanto se pensava. A realeza franca tornou-se, notadamente a partir da segunda metade do século VI, profundamente impregnada pelos princípios cristãos, muito antes, portanto, da unção e da coroação de Pepino, o Breve, na metade do século VIII. Ver, por exemplo, GEARY, P. Naissance de la France. Le monde mérovingien. Paris, 1989.
} 
sociedades sincrônicas, próximas umas das outras no espaço. A leitura criteriosa das bibliografias deveria induzir à formulação de questões e problemas novos, permitindo discernir "as influências" exercidas por uma sociedade sobre a vizinha. Concluía que "submetidas, em razão de sua proximidade e de seu sincronismo, à ação das mesmas grandes causas" seria possível "remontar, pelo menos parcialmente, a uma origem comum." ${ }^{15}$

Fiel à crítica das limitações impostas pelo nacional, afirmava que "a unidade do lugar é apenas desordem. Somente a unidade do problema apresenta um centro". ${ }^{16}$ Enfatizava que não havia nada mais perigoso para qualquer ciência que a tentação de olhar o presente e entendê-lo como "natural". Dessa maneira, apenas a abordagem da história comparada poderia indicar a existência de um problema diante de fenômenos aceitos como naturais e que aparentavam não necessitar de explicação. Porém, tinha claro que o avanço da história comparada seria lento, pois supunha estudos detalhados de fatos solidamente documentados e de ensinamentos fornecidos por trabalhos produzidos em outros países. Em suma, para ele, a história comparada animaria os estudos locais e nacionais, dos quais dependia; mas sem a ajuda da comparação, não poderiam acontecer avanços na historiografia nacional.

O próprio Bloch, sabendo que o trabalho comparativo estaria reservado a poucos, diria mais tarde que seus colegas expressaram sua polida aprovação ao artigo e voltaram para seus trabalhos sem mudar seus hábitos. HeinzGerhard Haupt em "O lento surgimento de uma história comparada" tem outra explicação para a pouca receptividade do artigo de Bloch na França ${ }^{17}$ Entende que o problema está referido à própria construção da história da França pela historiografia. A Revolução Francesa é percebida como um acontecimento primordial, um centro irradiador de idéias e práticas que, ao se espalharem pelo mundo, despertaram adesão entusiasta e provocaram rupturas importantes. Desse modo, os historiadores franceses vêem a Revolução como um dos mitos fundadores da França moderna, como modelo da história contemporâ-

\footnotetext{
${ }^{15}$ BLOCH, Marc. "Pour une Historie Comparée des societés européennes". Op. cit., p.19.

${ }^{16}$ BLOCH, Marc. "Une étude régionale: Géographie ou Histoire?". Annales d'Histoire Economique et Sociale, no.6, janeiro de 1934, citado por SKOCPOL, Theda; SOMERS, Margaret. "The uses of Comparative History in macrosocial inquiry", Comparative Studies in Society and History, vol. 22, $\mathrm{n}^{\circ}$ 2, 1980. p. 194.
} 
nea para o mundo ocidental. Portanto, caberia às outras sociedade e culturas se compararem à França e não ocorrer o oposto.

Raymond Grew, historiador e editor por muitos anos da importante revista, Comparative Studies in Society and History, propõe um diálogo com Bloch em artigo de 1980. ${ }^{18}$ Essa revista, criada em 1958, edita tanto artigos que apresentam análises de material empíricos quanto de viés mais teórico referentes a todas as ciências sociais. Há muitos textos sobre antropologia, já que a comparação está intrinsicamente ligada à conformação desse campo do saber; também sobre sociologia, pois a comparação é muito familiar ao trabalho dos sociólogos que, muitas vezes, atravessam os limites do tempo e da nação e buscam exatamente as generalizações; menos contemplados são a ciência política e a história. ${ }^{19}$

Grew é um entusiasta da história comparada, e entende que o "chamado à comparação" permanece aberto para a quantificação, para a construção de modelos, para teorizações e para aproximações entre sociedades diversas e entre períodos históricos. Porém, afirma ele, não há propriamente um método comparativo. Embora Bloch tenha sempre se referido a um método comparativo, Grew entende que o historiador francês propunha mais um modo de pensar do que um método; o uso da comparação era uma maneira de alcançar diferentes perspectivas no campo da pesquisa. Constitui-se em modelo que prescinde da elaboração de estruturas formais e que se apresenta mais como uma forma de pensar o objeto do que como uma metodologia.

Dez anos depois, em 1990, o mesmo Grew faz uma reflexão sobre o estado dos estudos comparativos e mostra uma visão otimista. Afirma que a comparação ganhou mais respeitabilidade e um número maior de adeptos. "O

\footnotetext{
${ }^{17}$ HAUPT, Heinz-Gerhard. "La lente émergence d'une histoire comparée”. In: BOUTIER, Jean; DOMINIQUE, Julia (Dir.). Passés recomposés. Champs et chantiers de l'Histoire. Paris: Autrement, 1995.

${ }^{18}$ GREW, Raymond. "The case for comparing histories", The American Historical Review, vol. $85, \mathrm{n}^{\circ} 4,1980$. Outros trabalhos do autor abordando a comparação: GREW, Raymond. "The Comparative Weakness of American History". Journal of Interdisciplinary History, vol. XVI, nº 1, 1985. pp. 87-101; GREW, Raymond; BURGUIÈRE, André (Eds.). Construction of minorities: cases for comparison across time and around the world. University of Michigan Press, 2001.

${ }^{19}$ Ver, entre outros, HAMMEL, E. A. "The comparative method in anthropological perspective", Comparative Studies in Society and History, vol. 22, n 2, 1980. pp. 145-155; BONNELL, Victoria E. "The uses of theory, concepts and comparison in Historical Sociology", Comparative Studies in Society and History, vol. 22, n 2, 1980. pp. 156-173.
} 
chamado à comparação desligado de qualquer particular modo de análise, permanece ecleticamente aberto à quantificação, à construção de modelos, pequenas e grandes teorias, e à comparação dentro das sociedades e períodos assim como através daquelas convencionais divisões de experiência social." ${ }^{20}$ Repete as mesmas idéias defendidas anteriormente e se alinha como discípulo de Marc Bloch: "Os usos menos formais da comparação - para quebrar velhos padrões de pensamento, para fazer perguntas importantes que ainda não haviam sido postas e para modelar percepções para significativos problemas históricos que se transformam em possíveis tópicos de pesquisa - são os menos comuns ou pelo menos os menos discutidos na escrita acadêmica. Esse criativo uso da comparação para estimular a imaginação é o uso da comparação que Marc Bloch tinha em mente em seu famoso ensaio. Usando a comparação para ganhar uma diferente perspectiva no campo da pesquisa e para reformular sua abordagem, ela não requer estruturas formais." ${ }^{21}$

As diferenças entre o trabalho do historiador e de outros cientistas sociais, no que se refere a procedimentos metodológicos com relação à comparação, ganham clareza quando acompanhamos o artigo de Theda Skocpol e Margaret Somers, The uses of comparative history in macrosocial inquiry. ${ }^{22}$ Este texto é uma importante referência, pois traz uma consistente reflexão metodológica sobre a questão. As autoras elaboram sua análise a partir da leitura de um significativo número de estudos de cientistas sociais, dividindo esses trabalhos de acordo com certos critérios metodológicos. Reconhecendo as contribuições de John Stuart Mill e de Max Weber para se pensar a história comparada, o texto aponta para a existência de pelo menos três distintas lógicas no uso da história comparada: a) demonstração paralela de teoria; b) contraste de contextos; c) análise macro-causal. Na primeira lógica, o analista justapõe casos históricos

\footnotetext{
${ }^{20}$ GREW, Raymond. "On the current state of comparative studies". In: ATSMA, Hartmut; BURGUIÈRE, André. (Orgs.) Op. cit., p.326

${ }^{21}$ Idem, ibidem, p.331.

${ }^{22}$ SKOCPOL, Theda; SOMERS, Margaret. "The uses of Comparative History in macrosocial inquiry" Op. cit. As autoras têm outros trabalhos em que adotam a perspectiva da comparação. Ver: SKOCPOL, Theda. States and social revolutions: a comparative analysis of France, Russia and China. Cambridge; New York: Cambridge University Press, 1979; SOMERS, Margaret; GOLDFRANK, Walter. "The limits of agronomic determinism: a critique of Paige's agrarian revolution", Comparative Studies in Society and History, vol. 23, n 3, 1979.
} 
para persuadir o leitor de que a delineada hipótese e (ou) a teoria elaboradas a priori podem ser demonstradas repetidamente. Desse modo, o estudioso elabora modelos teóricos e hipóteses antes de trabalhar "os casos ilustrativos" ${ }^{23} \mathrm{Na}$ segunda lógica, o objetivo é mostrar que uma dada teoria pode se sustentar de caso para caso. Há uma ênfase nos fatores únicos de cada caso particular e na demonstração dos contrastes que se desenham entre cada caso individual. Para se chegar a tais contrastes, o analista é ajudado pela escolha de grandes temas ou de determinadas questões ou, ainda, por conceitos de "tipo ideal". A integridade histórica de cada caso é cuidadosamente respeitada. As autoras referemse mais longamente ao clássico, Nation-Building and Citizenship, de Reinhart Bendix. Este afirma que os estudos comparativos aumentam "a visibilidade" de uma estrutura em contraste com outra. Por exemplo, o feudalismo europeu pode ser mais agudamente definido por comparação, por exemplo, com o feudalismo japonês. ${ }^{24} \mathrm{~A}$ terceira lógica, a da história comparada como análise macrocausal, tem por finalidade chegar a inferências causais, trabalhando o nível das macro estruturas ou processos. Tomando um número limitado de casos, este procedimento tem a virtude de tentar validar (ou invalidar) hipóteses causais sobre macro-fenômenos, podendo levar, com a abordagem comparativa, a novas generalizações históricas. Como exemplo, citam o trabalho - segundo as autoras, de ambição sem paralelos - de Barrington Moore Junior que, em busca das origens sociais da democracia e da ditadura no mundo contemporâneo, identifica três possíveis rotas históricas que levaram a tais regimes políticos: a) da "revolução burguesa" em direção à democracia liberal; b) da "revolução por cima" ao fascismo; c) da "revolução camponesa" ao comunismo. Moore pretende demonstrar como a preferência por certas alianças sociais explica configurações políticas favoráveis ou desfavoráveis para o estabelecimento da moderna democracia ocidental - por exemplo, as desastrosas consequiências para a democracia da coalizão entre as elites agrárias e industriais na Alemanha do século XIX. ${ }^{25}$

\footnotetext{
${ }^{23}$ Um exemplo dessa lógica é o trabalho de EISENSTADT, S. N. The political systems of empires: the rise and fall of historical bureaucratic societies. New York: Free Press, 1963.

${ }^{24}$ BENDIX, Reinhard. Nation-Building and Citizenship. Berkeley; Los Angeles: University of California Press, 1977.

${ }^{25}$ MOORE JR, Barrington. Social origins of dictatorship and democracy: lord and peasant in the making of the modern world. Boston: Beacon Press, 1966.
} 
Esta brevíssima passagem pelo artigo das sociólogas teve o objetivo de indicar as diferenças epistemológicas entre o trabalho do historiador e o dos cientistas sociais. O historiador não está à procura de generalizações e não constrói suas análises a partir de modelos elaborados a priori. Nesse sentido, o já citado livro de Almond e Verba se constitui em exemplo de como um modelo elaborado a partir de uma visão etnocêntrica pode produzir resultados questionáveis.

\section{Brasil e América Latina}

A historiografia latino-americana, do mesmo modo que a européia, demonstra que os estudos comparativos, ainda que escassos, têm sido uma constante, a começar pelo grande historiador mexicano Silvio Zavala que, em 1935, apresentava um texto no qual comparava semelhanças e diferenças relativas à conquista espanhola nas ilhas das Canárias e na América. ${ }^{26}$

O artigo/balanço, de 1982, de Magnus Morner, Julia Fawaz de Viñuela e John French, Comparative approaches to Latin American History, indica que os historiadores têm preferência por comparar certos temas - escravidão, relações raciais, imigração, fronteiras e urbanização - e defende o método como capaz de trazer contribuições inovadoras à historiografia. ${ }^{27}$ Os objetivos da comparação podem, na perspectiva dos autores, ser assim resumidos: a) formular generalizações por meio de observações de recorrências; b) demonstrar as singularidades por intermédio da observação das diferenças; c) ajudar a produzir explicações causais. Desse modo, os autores mantêm-se filiados a uma perspectiva metodológica que busca "as causas gerais" dos fenômenos históricos, pretende chegar a generalizações e se aproximam da construção de modelos. Distinguem os estudos de história comparada daqueles que praticam a "simples justaposição de relatos descritivos" e que, por isso, não alcançam o objetivo proposto. Tais trabalhos se restringem, segundo eles, à mera

\footnotetext{
${ }^{26}$ ZAVALA, Silvio A. Las conquistas de Canarias y América. Las Palmas: Cabildo Insular de Gran Canaria, 1991.

${ }^{27}$ FRENCH, John D.; MÖRNER, Magnus; VIÑUELA, Julia Fawaz. "Comparative Approaches to Latin American History”. Latin American Research Review, vol. 17, n 2, pp. 55-89.
} 
"classificação" de países, mostrando apenas sociedades com um certo número de variáveis não integradas em uma moldura analítica.

A história comparada deve, portanto, fugir das justaposições e das classificações. Na minha perspectiva, também não deve estar comprometida com a busca de generalizações; a produção acadêmica latino-americana, das décadas de 1960 e 1970, foi claramente marcada por essa discutível visão generalizante. Cientistas sociais estudaram a região a partir de uma perspectiva totalizante com ênfase na macro-história que privilegiava as estruturas econômicas e sócias. Dessa maneira, a América Latina era apresentada com semelhantes características históricas e com problemas similares a serem enfrentados no presente: pobreza, atraso, em uma palavra, subdesenvolvimento. Desse modo, o processo histórico da região poderia ser entendido a partir de categorias explicativas previamente construídas. O melhor exemplo são os ensaios que se dedicaram a trabalhar com a "teoria da dependência" na América Latina. Ainda que os textos mais sofisticados se preocupassem com as nuances nacionais, comumente a explicação generalizante se estendia nos seus traços mais fortes por todos os países latino-americanos. ${ }^{28}$

Relacionado a essa questão, outro problema de abordagem da história da América Latina precisa ser destacado: uma certa visão que transportava para o cenário latino-americano modelos de interpretação histórica já estabelecidos e próprios da história européia. Como exemplos desse período, salientamos os debates sobre a natureza das revoluções burguesas e socialistas. Outro caso emblemático, nos anos 60 e 70, refere-se aos estudos sobre o movimento operário. A historiografia esperava encontrar nas sociedades latino-americanas o mesmo comportamento político e a mesma organização sindical que haviam criada "a consciência de classe" do proletariado europeu. Os autores se decepcionavam ao fazer a comparação e assumiam uma certa hierarquização apoiada em determinados juízos de valor assumidos a priori, escalonando dos mais "avançados" movimentos sociais europeus aos mais "atra-

\footnotetext{
${ }^{28}$ São vários os textos que abordam a problemática da dependência na América Latina. Duas obras referenciais sobre o tema são: CARDOSO, Fernando Henrique e FALETTO, Enzo. Dependência e desenvolvimento na América Latina. Ensaio de interpretação sociológica. $7^{\mathrm{a}}$ ed., Rio de Janeiro: Guanabara, 1986. JAGUARIBE, Helio et. al., La dependencia político-económica de América Latina. México: Siglo XXI, 1970.
} 
sados" latino-americanos que, por seu turno, ainda teriam um longo caminho a percorrer até chegar ao patamar idealizado.

Nos anos recentes, alguns historiadores aceitaram os desafios propostos pela história comparada e escaparam das armadilhas das generalizações e do eurocentrismo. Farei referência a dois livros bem sucedidos, os de Maria Helena Capelato e de José Luis Bendicho Beired, escolhidos entre outros trabalhos. ${ }^{29} \mathrm{Na}$ esteira das reflexões de Marc Bloch, ambos elegeram grandes temas da historiografia e à luz das bibliografias nacionais e das fontes arroladas, propuseram perguntas novas e levantaram interrogações inéditas. O livro de Beired sobre os intelectuais autoritários no Brasil e na Argentina, entre 1914 e 1945, contribui de maneira significativa para a compreensão das convergências e das particularidades dos nacionalistas de direita nos dois países. ${ }^{30}$ Trabalhando com o conceito de campo de Bourdieu, o autor pode equacionar "as sub-divisões da direita nacionalista como um dado constitutivo e definidor de sua própria conformação". Desenhou os campos intelectuais nos dois países a partir de certos pólos ideológicos. Encontrou na Argentina, uma estrutura diática - católica e fascista; e no Brasil, uma estrutura triádica - católica, fascista e cientificista. Essa corrente cientificista desempenhará papel central nas diretrizes do governo Vargas durante o Estado Novo. Ao lado das idéias e posturas nacionalistas, antiliberais e anti-democráticas, próprias dos autoritários nos dois países, Beired identificou as singularidades de cada uma das situações. Em sua conclusão, afirma que "apresentamos certas analogias en-

\footnotetext{
${ }^{29}$ Ver a tese de doutoramento de Gabriela Pellegrino Soares, A semear horizontes: leituras literárias na formação da infância, Argentina e Brasil (1915-1954), História Social, FFLCH, USP, 2002, na qual a autora faz uma inspirada análise sobre literatura infantil, educadoras culturais, experiências bibliotecárias e editoras nos dois países. Outra referência interessante é o livro de Mariana Martins Villaça, Polifonia tropical.Experimentalismo e engajamento na música popular (Brasil e Cuba, 1967-1972), São Paulo, Humanitas/História Social, 2004, em que compara o movimento Tropicalista no Brasil e a Nueva Trova em Cuba. Conferir, ainda, o original trabalho de Marco A. Pamplona, Revoltas, repúblicas e cidadania, Rio de Janeiro, Record, 2003, em que discute esses temas nas cidades do Rio de Janeiro e de Nova York no período da consolidação da ordem republicana. E, também, Maria Ligia Coelho Prado, "Universidade, Estado e Igreja na América Latina" e "Natureza e identidade nacional nas Américas". In: América Latina no século XIX: tramas, telas e textos. São Paulo; Bauru: Edusp; Edusc, 1999.

${ }^{30}$ BEIRED, José Luis Bendicho. Sob o signo da nova ordem. Intelectuais autoritários no Brasil e na Argentina (1914-1945). São Paulo: Edições Loyola, 1999.
} 
tre ambos os nacionalismos de direita, analisamos as configurações dos campos intelectuais, estudamos algumas de suas propostas e representações fundamentais, constatamos a existência de semelhanças e diferenças, e buscamos explicá-las historicamente". ${ }^{31}$

O livro de Capelato compara varguismo e peronismo, tendo como questão central "compreender o caráter autoritário da propaganda política veiculada pelos meios de comunicação, educação e produção cultural para conquistar "os corações e mentes". ${ }^{32}$ Recortou grandes questões, como identidade nacional, cidadania e cultura política, analisou um conjunto de fontes da mesma natureza produzidas nos dois países e desvendou semelhanças e diferenças entre as práticas autoritárias varguista e peronista. Mostrou que algumas das diferenças entre os dois regimes podem ser explicadas pela decisão de Vargas de absorver muitas das idéias da "direita cientificista" (em aberto diálogo com Beired). Nas suas conclusões, acompanha-se o diálogo acima mencionado: "A análise da propaganda política procurou apontar essas diferenças: enquanto a propaganda peronista empenhou-se em mostra a "nova Argentina" como uma sociedade mais justa e mais livre da dependência externa, a propaganda estadonovista explorou os aspectos positivos da construção de um Estado Novo mais organizado e eficaz na conquista do progresso, considerado base indispensável para a edificação de uma sociedade mais justa no futuro. Essas diferenças de objetivos e prioridades permitem esclarecer por que o peronismo se definiu como uma "revolução social" enquanto o advento do estado Novo era identificado como uma "revolução política" concentrada na reforma do Estado." ${ }^{33}$ Interessantes também são suas reflexões sobre as "heranças" dos movimentos varguista e peronista e a persistência dos mitos em torno deles. Enquanto no Brasil, o varguismo é uma lembrança bem construída pela memória oficial, com o auxílio da máquina de propaganda e recordada com nostalgia pelos trabalhadores que foram beneficiados pelas leis trabalhistas do governo, na Argentina, o peronismo é muito mais que uma lembrança, constituin-

\footnotetext{
${ }^{31}$ Idem, ibidem, p.277.

${ }^{32}$ CAPELATO, Maria Helena R. Multidões em cena. Propaganda política no varguismo e no peronismo. Campinas: Papirus, 1998. p.19.

${ }^{33}$ Idem, ibidem, p. 283.
} 
do-se em uma força política sustentada pela permanência de mitos que ainda mobilizam a sociedade.

O recente livro de Boris Fausto e Fernando Devoto, Brasil e Argentina. Um ensaio de história comparada (1850-2002) se apresenta com outra proposta. Tem o formato de um manual de referência, abrangendo um longo período histórico. ${ }^{34}$ Os autores esperam, como afirmam na introdução, que "historiadores e cientistas sociais encontrem [com a leitura do livro] alguns novos pontos de reflexão, ou pelo menos lugares diferentes de onde olhar os problemas de suas respectivas nações e que aqueles que atuam em esferas de decisão possam encontrar nesse passado motivos adicionais para uma colaboração mais estreita entre as duas nações." 35 Ao lado dos méritos incontestes do trabalho, a ausência de um seleto e substantivo elenco de problemas colocados de antemão aos pesquisadores produz um resultado final mais próximo à justaposição das duas histórias nacionais, marcando-se semelhanças e diferenças entre os dois países.

\section{Globalização e histórias conectadas}

Da mesma forma que o ambiente pós Primeira Guerra Mundial explica, em parte, as críticas de Henri Pirenne e de Marc Bloch ao confinamento dos historiadores dentro dos espaços nacionais, os tempos recentes de avanço da globalização propicia a discussão sobre a construção de histórias conectadas. Em artigo publicado em 2001, Les mondes melés de la monarchie catholique et autres 'connected histories', Serge Gruzinski defende a ampliação do olhar do historiador para além da nação, propondo que se estabeleçam conexões. ${ }^{36}$ A expressão histórias conectadas foi proposta por Sanjay Subrahmanyam, historiador indiano radicado na França, que desmonta o que considera ser a "visão tradicional" da historiografia européia sobre o mundo asiático. ${ }^{37}$

\footnotetext{
${ }^{34}$ FAUSTO, Boris e DEVOTO, Fernando. Brasil e Argentina. Um ensaio de história comparada (1850-2002). São Paulo: Editora 34, 2004. De acordo com tal formato, não há no livro notas de rodapé, nem conclusão.

${ }^{35}$ Idem, ibidem, p. 28.

${ }^{36}$ GRUZINSKI, Serge. "Les mondes mêlés de la Monarchie catholique et autres 'connected histories' "Op. cit.

${ }^{37}$ SUBRAHMANYAM, Sanjay. "Connected histories: notes towards a reconfiguration of early modern Eurasia”. In: LIEBERMAN, Victor (Ed.). Beyond Binary Histories. Reimagining Eursaia to c. 1830. Ann Arbor: The University of Michigan Press, 1999.
} 
Enfatiza que a história da Eurásia moderna não pode ser vista como mero produto ou resultado do "comando" da história européia, sem a qual, supostamente, não existiria. Propõe que ela seja entendida em suas conexões com a Europa e com as outras partes do mundo, sem que se estabeleçam pólos, um determinante e outro subordinado. ${ }^{38}$

Essa perspectiva se aproxima da indicada por Michel Espagne que elaborou o conceito de tranferts culturels para pensar conexões entre duas culturas diferentes. Para ele, devem-se buscar objetos de pesquisa que façam aparecer pontos de contato reais e não simplesmente formais entre duas sociedades distintas. Por exemplo, a presença estrangeira num país, fenômenos de fronteira, figuras de mestiçagem cultural. Espagne enfatiza a importância da comparação, mas alerta para a necessidade de fugir da projeção de um ponto de vista nacional sobre o outro. ${ }^{39}$

Voltando ao artigo de Gruzinski, nota-se que sua escolha para demonstrar a eficácia da tecitura de conexões históricas é precisa: o momento da história ibérica no qual aconteceu a "união" das coroas espanhola e portuguesa. Critica a história comparada, afirmando que foi uma alternativa para alargar os horizontes dos historiadores, mas que, muita vezes, propiciou o ressurgimento insidioso do eurocentrismo. Aponta algumas exceções, como o já citado livro de Sérgio Buarque, Raízes do Brasil, mas que se constituem - segundo ele - em casos isolados da produção latino-americana.

Associa a visão eurocêntrica daqueles que trabalham com a história da América Latina com as perspectivas dualistas: o ocidente e os outros, os es-

\footnotetext{
${ }^{38}$ Chakrabarty, indiano radicado nos Estados Unidos, propõe que o olhar do historiador não fique restrito ao espaço nacional, critica a perspectiva eurocêntrica e defende uma abordagem transnacional, uma vez que há contatos constantes entre culturas e sociedades. Ver CHAKRABARTY, Dipesh. Provincializing Europe. Postcolonial thought and historical difference, Princeton, Princeton University Press, 2000.

${ }^{39}$ Conforme Michel Trebitch: "O ataque principal de M. Espagne, apoiado essencialmente no exemplo franco-alemão, se dirige ao fato de que a comparação opera sempre dentro de um ponto de vista nacional, o que impede de elaborar verdadeiras ferramentas comparativas, confinando-se dentro de categorias puramente abstratas". TREBITCH, Michel. "L'histoire comparée des intellectuels comme histoire expérimentale", in TREBITCH, Michel e GRANJON, Marie-Christine (eds.). Pour une histoire comparée des intelectuels. Bruxelas, Complexe, 1998. Ver ESPAGNE, Michel. "Sur les limites du comparatisme en histoire culturelle". Genèses, no.17, setembro de 1994. Ver, ainda, BEIRED, José Luis B. A construção de identidades nacionais no mundo americano e ibérico. Mimeo., 2005.
} 
panhóis e os índios, os vencedores e os vencidos, em suma, as análises sistematicamente concebidas em termos de alteridade. A solução seria trabalhar com histórias conectadas, pois elas são múltiplas e ligadas entre si, comunicando-se umas com as outras. Tal postura está de acordo com a elaboração de seu conceito de mestiçagem resultante do encontro de vários universos culturais na América - o indígena, o europeu, o africano, o asiático - que se manifesta na produção das técnicas, das artes e das leis.

Valoriza a figura dos passeurs, mediadores entre os diversos grupos e sociedades e portadores das possibilidades das conexões. Para demonstrar sua perspectiva, afirma que as fontes referentes à história da Nova Espanha desvendam paisagens misturadas, sempre imprevisíveis e nos confrontam com processos que pertencem a vários espaços ao mesmo tempo. ${ }^{40}$ Pensando um mundo em trânsito para a "globalização" e insistindo nas ligações, lança uma série de exemplos de homens que circulavam entre os vários continentes. O dramaturgo Juan Ruiz de Alarcón atravessou o Atlântico três vezes e seu rival, Tirso de Molina, duas. O mestiço peruano Garcilaso de la Vega viveu na Europa e publicou, em Lisboa, seu livro sobre a memória dos incas. A dilatação planetária dos espaços europeus pode ser medida pela constatação de que alguns textos europeus eram lidos por todo o mundo. "Uma famosa e divulgada obra de 'grande público', como Diana de Montemayor, encontrava leitores tanto às margens tropicais da baia de Salvador quanto nas vilas espanholas das Filipinas. Uma parte da primeira edição de Dom Quixote ecoava nos Andes. As fábulas de Esopo foram traduzidas ao nahuatl na cidade do México e ao japonês em Nagasaki..." ${ }^{4}$

A história comparada, desse modo, para ele, perde a riqueza e as nuances, fazendo permanecer a divisão entre os diversos mundos. A abordagem que enfatiza as conexões também se coloca na contramão dos modelos monográficos ao estilo norte-americano, que se caracterizam pela verticalidade. Gruzinski admite, finalmente, que as histórias conectadas supõem que o historiador tenha enorme erudição e notável maturidade intelectual, o que a restringe a uma minoria de estudiosos.

\footnotetext{
${ }^{40}$ GRUZINSKI, Serge. O pensamento mestiço. Trad. Rosa F. d'Aguiar. São Paulo: Companhia das Letras, 2001.

${ }^{41}$ GRUZINSKI, Serge. "Les mondes mêlés de la Monarchie catholique et autres 'connected histories' "Op. cit. p.93.
} 
Também inspirado pelos tempos atuais de globalização, o historiador português Antonio Nóvoa, ao contrário de Gruzinski, encontra na história comparada uma importante contribuição para se pensar os temas referidos à educação. No livro publicado em 1998, Histoire et comparaison. Essais sur l'éducation, analisa problemas das relações entre as esferas locais e globais. Afirma que a história da educação, disciplina nascida no século XIX, se afinava com o tempo histórico marcado pela consolidação dos sistemas nacionais de ensino. A noção de identidades nacionais foi constitutiva dos projetos educativos que pretendiam enquadrar os cidadãos dos novos Estados/nações. Uma reflexão comparada fazia parte desse conjunto para pensar as diferenças e semelhanças entre os diversos sistemas nacionais. No mundo atual, globalizado, continua a entender que é interessante a comparação. Aponta para a existência de um caráter transnacional de fenômenos, como a escola de massas ou a organização de currículos. Conclui que "a história comparada da educação tem um longo caminho a ser percorrido, notadamente no que concerne à produção de instrumentos metodológicos mais pertinentes. Mas é impossível passar ao largo das potencialidades desta linha de reflexão. Num mundo que, apesar do recrudescimento do nacionalismo, não pode mais ser imaginado no interior das fronteiras nacionais, é útil pensar uma história que se projeta numa pluralidade de espaços e lugares de pertencimento". ${ }^{42}$

\section{Para concluir}

Fazendo um balanço final, é indiscutível a constatação de que são poucos os estudos produzidos no Brasil que buscam comparar o Brasil aos demais países da América Latina. ${ }^{43}$ Mas creio que tal comparação é rica em potencialidades e contribuiria para a reflexão sobre novos problemas e questões. ${ }^{44}$

\footnotetext{
${ }^{42}$ NÓVOA, António. Histoire et comparaison. Essais sur l'Éducation. Lisboa: Educa, 1998. p.48.

${ }^{43}$ Sobre a distância que separa o Brasil dos demais países da América Latina, ver: PRADO, Maria Ligia Coelho. "O Brasil e a distante América do Sul". Revista de História, no.145, $2^{\circ}$.semestre de 2001, pp. 127-149; GUIMARÃES, Manuel Luís Salgado. "Nação e civilização nos Trópicos: o Instituto Histórico e Geográfico Brasileiro e o projeto de uma História Nacional”. Estudos Históricos, no. 1, 1998; CAPELATO, Maria Helena R. "O 'gigante brasileiro’ na América Latina: ser ou não ser latino-americano”. MOTA, Carlos Guilherme (org.). Viagem incompleta. A grande transação, São Paulo, Editora SENAC, 2000.

${ }^{44}$ É importante salientar que há um Programa de Pós-Graduação em Integração LatinoAmericana (PROLAM) na Universidade de São Paulo, que é interdisciplinar e mantém
} 
Penso, ainda, que a escolha da história comparada não exclui a abordagem de histórias conectadas. A única crítica metodológica indicada por Serge Gruzinski com relação à comparação refere-se à dificuldade de escapar da visão eurocêntrica e dos modelos dicotômicos. Do meu ponto de vista, é possível fazer história comparada e permanecer crítico das visões eurocêntricas e dicotômicas. Assim, entendo que há mais complementação entre comparação e conexão, do que exclusão. Voltando a Marc Bloch, seria extremamente fecundo, com o rigor e os procedimentos metodológicos próprios do ofício do historiador, buscar "a unidade do problema" em duas ou mais sociedades latino-americanas e promover as devidas conexões globalizantes.

Estou certa de que a produção historiográfica brasileira se enriqueceria se olhasse com mais atenção para as possibilidades da comparação e das conexões.

\section{Bibliografia}

ALMOND, Gabriel A.; VERBA, Sidney. The civic culture: political attitudes and democracy in five nations. Boston: Little Brown and Company, 1965.

ATSMA, Hartmut; BURGUIÈRE, André. (Orgs.). Marc Bloch aujourd'hui: histoire comparé et sciences sociales [Contributions au Colloque international organisé à Paris du 16 au 18 juin 1986 par l'École des hautes études en sciences sociales et l'Istitut historique allemand]. Paris: Éd. de l'École des hautes études en sciences sociales, 1990.

BEIRED, José Luis Bendicho. Sob o signo da nova ordem. Intelectuais autoritários no Brasil e na Argentina (1914-1945). São Paulo: Edições Loyola, 1999.

BENDIX, Reinhard. Nation-Building and Citizenship. Berkeley; Los Angeles: University of California Press, 1977.

BLOCH, Marc. "Pour une Historie Comparée des societés européennes". In: Mélanges historiques. vol. 1, Paris: S.E.V.P.E.N., 1963. pp. 16-40.

a exigência da comparação entre o Brasil e outro país latino-americano em todos os trabalhos de Mestrado e de Doutorado. O Programa já completou 10 anos com resultados muito positivos. Recentemente, foi criado na Universidade Federal do Rio de Janeiro (UFRJ) um interessante Programa de Pós-Graduação em História Comparada, indicando a importância desta abordagem. 
Os reis taumaturgos: o caráter sobrenatural do poder régio, França e Inglaterra. Trad. Júlia Mainardi. São Paulo: Companhia das Letras, 1993.

BONNELL, Victoria E. "The uses of theory, concepts and comparison in Historical Sociology", Comparative Studies in Society and History, vol. 22, $\mathrm{n}^{\circ} 2$, 1980. pp. 156-173.

CAPELATO, Maria Helena R. Multidões em cena. Propaganda política no varguismo e no peronismo. Campinas: Papirus, 1998.

. “O ‘gigante brasileiro' na América Latina: ser ou não ser latino-americano”. MOTA, Carlos Guilherme (org.). Viagem incompleta. A grande transação, São Paulo, Editora SENAC, 2000.

CARDOSO, Fernando Henrique e FALETTO, Enzo. Dependência e desenvolvimento na América Latina. Ensaio de interpretação sociológica. $7^{\mathrm{a}}$ ed., Rio de Janeiro: Guanabara, 1986.

ESPAGNE, Michel. "Sur les limites du comparatisme en histoire culturelle". Genèses, no.17, setembro de 1994.

FAUSTO, Boris e DEVOTO, Fernando. Brasil e Argentina. Um ensaio de história comparada (1850-2002). São Paulo: Editora 34, 2004.

FRENCH, John D.; MÖRNER, Magnus; VIÑUELA, Julia Fawaz. "Comparative Approaches to Latin American History". Latin American Research Review, vol. 17, n’ 2, pp. 55-89.

GREW, Raymond. "The case for comparing histories", The American Historical Review, vol. 85, nº 4, 1980.

GREW, Raymond. "The Comparative Weakness of American History". Journal of Interdisciplinary History, vol. XVI, $\mathrm{n}^{\circ}$ 1, 1985. pp. 87-101. . "On the current state of comparative studies". In: ATSMA, Hartmut; BURGUIÈRE, André. (Orgs.). Marc Bloch aujourd'hui: histoire comparé et sciences sociales [Contributions au Colloque international organisé à Paris du 16 au 18 juin 1986 par l'École des hautes études en sciences sociales et l'Istitut historique allemand]. Paris: Éd. de l'École des Hautes Études en Sciences Sociales, 1990.

GRUZINSKI, Serge, "Les mondes mêlés de la Monarchie catholique et autres 'connected histories' “. Annales HSS, n 1, janvier-février 2001. 
O pensamento mestiço. Trad. Rosa F. d'Aguiar. São

Paulo: Companhia das Letras, 2001.

GUIMARÃES, Manuel Luís Salgado. "Nação e civilização nos Trópicos: o Instituto Histórico e Geográfico Brasileiro e o projeto de uma História Nacional”. Estudos Históricos, no. 1, 1998

HAMMEL, E. A. "The comparative method in Anthropological Perspective", Comparative Studies in Society and History, vol. 22, n 2, 1980. pp. 145-155.

HAUPT, Heinz-Gerhard. "La lente émergence d'une histoire comparée". In: BOUTIER, Jean; DOMINIQUE, Julia (Dir.). Passés recomposés. Champs et chantiers de l'Histoire. Paris: Autrement, 1995.

HOBSBAWM, Eric. J. A era das revoluções: Europa, 1789-1848. Trad. Maria Tereza Lopes Teixeira. $7^{a}$ ed., Rio de Janeiro: Paz e Terra, 1989.

. Era dos extremos: o breve século XX: 1914-1991. Trad.

Marcos Santarrita. São Paulo: Companhia das Letras, 1995.

HOLANDA, Sérgio Buarque de. Raízes do Brasil. 22a ed., Rio de Janeiro: José Olympio, 1991.

Visão do Paraíso. Os motivos edênicos no descobrimento e colonização do Brasil. $5^{\text {a }}$ ed., São Paulo: Brasiliense, 1992.

JAGUARIBE, Helio et. al., La dependencia político-económica de América Latina. México: Siglo XXI, 1970.

MOORE JR, Barrington. Social origins of dictatorship and democracy: lord and peasant in the making of the Modern World. Boston: Beacon Press, 1966.

NÓVOA, António. Histoire et comparaison. Essais sur l'Éducation. Lisboa: Educa, 1998.

PAMPLONA, Marco A. Revoltas, repúblicas e cidadania, Rio de Janeiro, Record, 2003.

PIRENNE, Henri. "De la méthode comparative en histoire. Discours Prononcé à la Séance d'Ouverture du Ve Congrès International des Sciences Historiques. Bruxelles, 1923.

1931. pp. 5-22.

."La tâche de l'historien". Le Flambeau, vol. XIV, nº 8,

PRADO, Maria Ligia Coelho. "Universidade, Estado e Igreja na América Latina" e "Natureza e identidade nacional nas Américas". In: América Latina no século XIX: tramas, telas e textos. São Paulo; Bauru: Edusp; Edusc, 1999. 
“O Brasil e a distante América do Sul”. Revista de História, no.145, $2^{\circ}$.semestre de 2001.

SAID, Edward W. Orientalismo: o Oriente como invenção do Ocidente. Trad. Tomás R. Bueno. São Paulo: Companhia das Letras, 1990.

SKOCPOL, Theda. States and social revolutions: a comparative analysis of France, Russia and China. Cambridge; New York: Cambridge University Press, 1979.

SKOCPOL, Theda; SOMERS, Margaret. "The uses of Comparative History in macrosocial inquiry", Comparative Studies in Society and History, vol. 22, $\mathrm{n}^{\mathrm{o}} 2,1980$.

SOARES, Gabriela Pellegrino. A semear horizontes: leituras literárias na formação da infância, Argentina e Brasil (1915-1954), Tese de Doutoramento, História Social, FFLCH, USP, 2002.

SUBRAHMANYAM, Sanjay. "Connected histories: notes towards a reconfiguration of early modern Eurasia”. In: LIEBERMAN, Victor (Ed.). Beyond Binary Histories. Re-imagining Eurasia to c. 1830. Ann Arbor: The University of Michigan Press, 1999.

TOCQUEVILlE, Alexis de. A democracia na América. Trad. Neil Ribeiro da Silva. $3^{a}$ ed., São Paulo: Edusp, 1987.

TREBITCH, Michel. "L'histoire comparée des intellectuels comme histoire expérimentale", in TREBITCH, Michel e GRANJON, Marie-Christine (eds.). Pour une histoire comparée des intelectuels. Bruxelas, Complexe, 1998.

VILLAÇA, Mariana Martins. Polifonia tropical. Experimentalismo e engajamento na música popular (Brasil e Cuba, 1967-1972), São Paulo, Humanitas/ História Social-USP, 2004.

ZAVALA, Silvio A. Las conquistas de Canarias y América. Las Palmas: Cabildo Insular de Gran Canaria, 1991. 